Research Square
Preprints are preliminary reports that have not undergone peer review.

They should not be considered conclusive, used to inform clinical practice, or referenced by the media as validated information.

\title{
Halloysite Nanotubes (HNTs)-filled Ethylene-propylene-diene Monomer/styrene-butadiene Rubber (EPDM/SBR) Composites: Mechanical, Swelling, and Morphological Properties
}

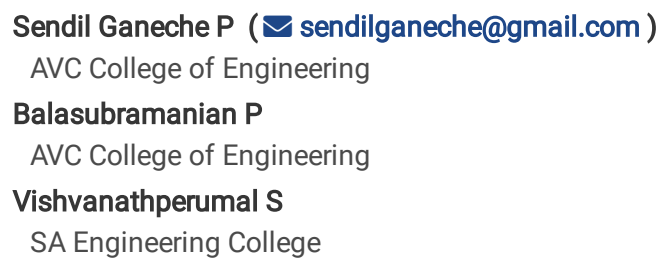




\section{Abstract}

Halloysite nanotubes (HNTs) were incorporated into an EPDM/SBR rubber/styrene-butadiene rubber (SBR) composite by melt blending of HNTs into the EPDM/SBR blend. The mechanical properties, abrasion and swelling resistance of HNTs ranging from 2 parts per hundred rubber (phr) to 10 parts per hundred rubber (phr) were investigated in EPDM/SBR base rubber. Tensile strength, 100\% modulus (modulus at 100 percent elongation), elongation at break and tear strength were evaluated at ambient temperature using electric universal tensile testing equipment in accordance with ASTM D-412. Hardness, abrasion and swelling resistance were determined using Shore-A Durometer, DIN abrader and immersion techniques, respectively. The results show that increasing HNT content increased tensile strength, tear strength, hardness (stiffness), and crosslink density. The surface morphology of tensilefractured material was studied using field-emission scanning electron microscopy (FE-SEM). According to FE-SEM results, the most roughness of the surface was seen at HNTs filled rubber nano-composites.

\section{Introduction}

Without some kind of reinforcement, a rubber substance, whether polar or non-polar, has weak physico-mechanical properties [1]. The addition of a number of ingredients with special roles, such as curatives (activator, catalyst, and vulcanization or cross-linking agents), aids in the enhancement of those properties. At the present days, rubber and curatives materials are well-known and are not becomes an issue to any further extent. However, many academicians and researchers have recently improved the problem of modifying or replacing traditional additives such as carbon black (CB) and silica [24]. Because of their unique particle form and hydrophobic surface, $\mathrm{CB}$ is recommended as a strong reinforcement particle with better dispersibility in rubber matrix [5]. In addition, CB particle caused pollution in atmosphere and displayed dark color in the composite [6-7]. Due to its hydrophilic surface, silica is recognised as a white filler with similar reinforcement effect as CB and low dispersion in rubber matrices, which appears in natural rubber (NR) composite [5, 8]. As a result, a variety of researchers [9-13] have introduced new types of nano-fillers, such as clay particles, to enhance the mechanical and swelling properties of rubber composites. They are also layered silicates and belong to the phyllosilicate group, which includes montmorillonite, saponite, and hectorite.

Halloysite nanotubes (HNTs) have been found to be effective as nanofillers in a variety of rubber materials [14-15]. HNTs are a two-layered aluminosilicate $\left(\mathrm{Al}_{2} \mathrm{Si}_{2} \mathrm{O}_{5}(\mathrm{OH})_{4} \cdot \mathrm{H}_{2} \mathrm{O}\right)$ with a hollow tubular structure in the micron range and chemically similar to kaolin particles [16-17]. $\mathrm{HNTs}$ are a type of phyllosilicates material that consists of one octahedral sheet and one tetrahedral sheet with six-membered rings and 1:1 layers. The crystalline structure of HNTs is double layered. The outer layer surface of HNTs has Si-O groups, while the inner side surface and tube edges have $\mathrm{Al}(\mathrm{OH})_{3}$ - $\mathrm{groups}$ [18]. HNTs have a higher aspect ratio than clay minerals (montmorillonite, saponite, and hectorite) due to their tuber shape. HNTs have an aspect ratio ranging from 10 to 130, depending on the tube dimension. HNTs' large surface area and aspect ratio are likely to have a unique reinforcing impact on the polymer matrix. For nanocomposites to improve their mechanical and thermal properties, good interaction and interfacial adhesion between the rubber matrix and nano-filler particles are essential [19].

This work is an important accountability in the creating of new material of EPDM/SBR nanocomposites filled with various contents of HNTs. The objective of this paper is to explain the reinforcing ability of EPDM/SBR nanocomposites on the mechanical and swelling properties.

\section{Experimental}

\subsection{Materials}

Sigma-Aldrich supplied the halloysite nanotubes (HNTs) and swelling chemicals. The HNTs had a relative density of $2.53 \mathrm{~g} / \mathrm{cm}^{3}$ and a basic surface area of $65 \mathrm{~m}^{2} / \mathrm{g}$. The tubes had a diameter of $40-80 \mathrm{~nm}$ and a length of 1 to 4 micrometres. Arihant Reclamation Private Limited, Delhi, India, provided ethylene-propylene-diene monomer (EPDM) rubber (KEP-270) and styrene-butadiene rubber (SBR-1502). Vishvanathperumal et al [9] go into great detail about EPDM and SBR.

\subsection{Preparation of nanocomposites}

In an open mill mixer, EPDM rubber, styrene-butadiene rubber (SBR), Halloysite nanotubes (HNTs), and other ingredients (zinc oxide, stearic acid, tetramethylthiuram disulfide (TMTD), mercaptobenzothiazyl disulfide (MBTS), and sulphur) were mixed together $\left(50^{\circ} \mathrm{C}\right)$. The friction ratio is maintained in mixer is 1:1.4. Stage 1: Before mixing, rubber was passed 9-10 times between the mill rollers having a less than $1 \mathrm{~mm}$ nip gap. Stage 2: After homogenization of both the rubber (i.e., EPDM and SBR), the other ingredients like activator (zinc oxide and stearic acid), accelerator (TMTD and MBTS), and curing agent (sulphur) were added according to Table 1. For preparing various samples of EPDM/SBR blends, the amount of HNTs were different proportion as shown in Table 1. A semi-automated electrically powered hydraulic press was used to shape the composites sheet with a thickness of 2 mm. At a pressure of $30 \mathrm{MPa}$, the press temperature was held at $160^{\circ} \mathrm{C}$ for a 10 minute cure time. 
Table 1

Formulation of EPDM/SBR-HNTs Compounds

\begin{tabular}{|lllllllll|}
\hline Sample code & \multicolumn{8}{l|}{ Compounds (phr) } \\
\cline { 2 - 10 } & EPDM & SBR & HNTs & Zinc oxide & Stearic acid & MBTS & TMTD & Sulphur \\
\hline $\mathrm{H}_{0}$ & 80 & 20 & 0 & 4 & 1.5 & 1.2 & 1 & 2.5 \\
\hline $\mathrm{H}_{2}$ & 80 & 20 & 2 & 4 & 1.5 & 1.2 & 1 & 2.5 \\
\hline $\mathrm{H}_{4}$ & 80 & 20 & 4 & 4 & 1.5 & 1.2 & 1 & 2.5 \\
\hline $\mathrm{H}_{6}$ & 80 & 20 & 6 & 4 & 1.5 & 1.2 & 1 & 2.5 \\
\hline $\mathrm{H}_{8}$ & 80 & 20 & 8 & 4 & 1.5 & 1.2 & 1 & 2.5 \\
\hline $\mathrm{H}_{10}$ & 80 & 20 & 10 & 4 & 1.5 & 1.2 & 1 & 2.5 \\
\hline
\end{tabular}

Table 1 Formulation of EPDM/SBR-HNTs Compounds

\subsection{Testing and characterization of rubber composites}

EPDM/SBR nanocomposites were tested for tensile properties (tensile strength, elongation at break, and modulus) according to ASTM D-412. At ambient temperature, the tensile properties were calculated using a Universal Testing Machine (UTM) model Dak System Inc, T-72102, series 7200 with a crosshead speed of $500 \mathrm{~mm} / \mathrm{min}$. The tear strength is also measured in the same machine and conduction as per ASTM D-624. The hardness of the composites has been performed as per ASTM D-2240 by the Shore-A Durometer hardness tester. The abrasion characteristics of the rubber composite were measured using a DIN abrader according to ASTM D-5963 and are expressed in terms of volume loss. The swelling resistance was measured using the ASTM D-471 immersion process. At different temperatures of $30^{\circ} \mathrm{C}$, different penetrates such as aromatic, aliphatic, and chlorinated hydrocarbons are used to analyse the swelling properties of the composites. The mole percent uptake was calculated by this Eq. (2)

$$
Q_{t}(m o l \%)=\frac{\left(M_{t}-M_{0}\right) / M W}{M_{0}} \times 100
$$

where, $\mathrm{M}_{\mathrm{t}}=$ Final mass of the composite,

$\mathrm{M}_{0}=$ Initial mass of the composite

$\mathrm{MW}=$ Molecular weight of the penetrate.

The following Eq. (3) [33-35] was used to measure the degree of crosslinking density:

$$
\vartheta\left(\frac{m o l}{c m^{3}}\right)=\frac{1}{2 M_{C}}
$$

3

where, $\mathrm{M}_{\mathrm{C}}=$ Molar mass of the polymer between crosslinks.

The Flory-Rehner Eq. (4) was used to measure the molar mass between the crosslinks of the composites [33-36]:

$$
M_{C}\left(\frac{g}{m o l}\right)=\frac{-\rho_{p} V_{s} V_{r}^{1 / 3}}{\ln \left(1-V_{r}\right)+V_{r}+\chi V_{r}^{2}}
$$

4

where, $\rho_{p}=$ Polymer Density,

$\mathrm{V}_{\mathrm{s}}=$ Molar volume of the solvent $(106.3 \mathrm{~mL} / \mathrm{gmol})$,

$V_{r}=$ Volume fraction of the solvent-swollen filled polymer compound,

$\chi=$ Interaction parameter of the polymer (0.3) [37], and

$\mathrm{V}_{\mathrm{r}}$ can be determined by the following Eq. (5) [38]:

Loading [MathJax]/jax/output/CommonHTML/jax.js 


$$
V_{r}=\frac{1}{1+Q_{m}}
$$

5

where, $Q_{m}=$ Weight swell of the composites in toluene.

The tensile fractured surface of composites were observed with a Sigma with Gemini Column, CARL ZEISS FE-SEM, USA at the acceleration voltage of 10 $\mathrm{kV}$. The specimen surfaces were coated with gold with thickness of $10-20 \mathrm{~nm}$.

\section{Results And Discussion}

Figures 1-6 show the mechanical properties of EPDM/SBR-HNTs nanocomposites, with information of mechanical properties such as tensile strength, 100 percent modulus, elongation at break, tear strength, hardness, and abrasion resistance. From Fig. 1, it is observed that the tensile strength of base rubber is very low strength, which is ineffective in practical application and is why desires to be incorporated by nano-materials. The addition of HNTs to EPDM/SBR-HNTs nanocomposites will increase their tensile strength. When the addition of HNTs is about 10 phr, the tensile strength of rubber nanocomposites is about 109\% of that of base rubber blends. Furthermore, as the content of HNTs increased from 0 to 6 phr, the tensile strength increased rapidly due to better dispersion of nano-particles within the EPDM/SBR rubber matrix, and from 8 to 10 phr due to poor interaction, lesser agglomeration, and bonding between HNTs and EPDM/SBR matrix, which is responsible for the slight improvement in HNTs and rubber properties. As a result, the rubber-filler interfacial region's reinforcing effect of HNTs becomes extremely effective in influencing the tensile strength of EPDM/SBR-HNTs nanocomposites, resulting in increased tensile strength.

Figure 2 shows the modulus with different proportions of HNTs, calculated at $100 \%$ elongation. Figure 2 shows that as the HNTs loading in the EPDM/SBR composites increased, the modulus calculated at 100 percent elongation increased. The modulus at 100 percent elongation was used to determine the stiffness of the rubber composite. The 100 percent modulus was primarily influenced by the surface area, scale, and structure of HNTs. As a result, the composite with 6 phr of HNTs had a higher degree of cross-linking (as shown by the crosslinking density test), resulting in a higher 100 percent modulus. Since the composites filled with a higher amount of HNTs had a lower degree of chemical cross-linking, as shown by the cross-link density property in Fig. 7, the composites filled with a higher amount of HNTs had lower values. Low structural integrity, which is a significant parameter that can affect the characteristics of HNTs' reinforcing capacity, is also a result of high HNTs material. As a result, when compared to higher amounts of HNTs, the reinforcing impact of HNTs was reduced.

The effect of HNT loading on elongation at break is depicted in Fig. 3. With the addition of HNTs to the EPDM/SBR composites, the elongation at break decreased. The inter-tubular and interfacial bonding between the HNTs and the EPDM/SBR rubber matrix, as well as the better contact of the HNTs within the rubber matrix, play a key role in reducing the elongation at break. The improved interactions between the nano-filler and the rubber matrix increased the composites' strength and stiffness, reducing their ductility.

Figure 4 shows that as the HNTs were increased, the tear strength of the EPDM/SBR composites increased. The high crosslinking density of the HNTsloaded composites was responsible for the steady increase in tear strength with the inclusion of HNTs in the composite. As a result, it can be inferred that HNTs inhibited crack propagation, thereby increasing the composites' resistance. As a result, HNTs with high structural integrity have a fair resistance to crack propagation.

The mechanical property of rubber composites that is most significant is their hardness. Figure 5 illustrates the hardness of EPDM/SBR-HNT composites. The hardness of the composites varies depending on the amount of HNTs present. It begins at 53 Shore-A for unloaded compounds and steadily increases as the amount of HNTs in the HNTs nanofiller filled EPDM/SBR composites increases. The degree of cross-linking has a significant effect on the hardness of a compound. Furthermore, the HNTs' lower active surface area may have increased cross-links, which increased the composites hardness.

The abrasion loss of EPDM/SBR composites reinforced with HNTs is shown in Fig. 6. The abrasion resistance increases as the content of HNTs increases. This is due to the reinforcing effect of HNTs, which resulted in a stronger rubber-filler network. Furthermore, increasing the crosslinking density made the composites stiffer and more abrasion resistant.

The mole percent uptake of the rubber composites in different solvent (aromatic, aliphatic and chlorinated) at $30^{\circ} \mathrm{C}$ are shown in Table 2 . The mole percent uptake was considerably decreased for HNTs reinforced composites as compared to neat EPDM/SBR blends. The higher HNT reinforcement in the EPDM/SBR rubber matrix limits the swelling-induced expansion of the rubber chains. This makes it very difficult for the solvent to penetrate the gaps between the rubber molecules, lowering the mole percent uptake. Hence, the rubber blend composites have higher solvent barrier properties compared to neat EPDM/SBR blends. The trend was in the order of: dichloromethane $>$ chloroform $>$ benzene $>$ toluene $>$ xylene $>$ mesitylene $>n$-pentane $>$ n-hexane $>$ carbon tetrachloride $>$ n-heptane $>$ n-octane. The higher molecular weight of solvent exhibited the lowest absorption and vice-versa. From the Table 2 , mole percent uptake trend was in order of: chlorinated $>$ aromatic $>$ aliphatic.

Loading [MathJax]/jax/output/CommonHTML/jax.js 
Table 2

Mole percent uptake for different penetrant of composites material at $30^{\circ} \mathrm{C}$

\begin{tabular}{|c|c|c|c|c|c|c|c|c|c|c|c|}
\hline \multirow{3}{*}{$\begin{array}{l}\text { Sample } \\
\text { code }\end{array}$} & \multicolumn{11}{|c|}{ Mole percent uptake (mol\%) } \\
\hline & \multicolumn{4}{|l|}{ Aromatic } & \multicolumn{4}{|l|}{ Aliphatic } & \multicolumn{3}{|l|}{ Chlorinated } \\
\hline & Benzene & Toluene & Xylene & Mesitylene & $\begin{array}{l}\mathrm{n}- \\
\text { pentane }\end{array}$ & $\begin{array}{l}\text { n- } \\
\text { hexane }\end{array}$ & $\begin{array}{l}\mathrm{n}- \\
\text { heptane }\end{array}$ & $\begin{array}{l}\mathrm{n} \text { - } \\
\text { octane }\end{array}$ & Dichloromethane & Chloroform & $\begin{array}{l}\text { Carbon } \\
\text { tetrachloride }\end{array}$ \\
\hline $\mathrm{H}_{0}$ & 3.95 & 3.57 & 3.46 & 3.03 & 2.42 & 2.34 & 2.28 & 2.24 & 5.42 & 4.56 & 2.26 \\
\hline $\mathrm{H}_{2}$ & 3.65 & 3.28 & 2.71 & 2.46 & 2.16 & 2.02 & 1.95 & 1.87 & 4.86 & 4.17 & 1.94 \\
\hline $\mathrm{H}_{4}$ & 3.63 & 3.25 & 2.67 & 2.39 & 2.03 & 1.98 & 1.81 & 1.756 & 4.62 & 4.17 & 1.86 \\
\hline $\mathrm{H}_{6}$ & 3.59 & 3.17 & 2.63 & 2.36 & 1.96 & 1.95 & 1.83 & 1.72 & 4.56 & 4.08 & 1.75 \\
\hline $\mathrm{H}_{8}$ & 3.58 & 3.14 & 2.65 & 2.35 & 2.04 & 1.92 & 1.86 & 1.8 & 4.54 & 4.03 & 1.87 \\
\hline $\mathrm{H}_{10}$ & 3.52 & 3.09 & 2.59 & 2.28 & 1.92 & 1.87 & 1.78 & 1.74 & 4.42 & 3.86 & 1.76 \\
\hline
\end{tabular}

Table 2. Mole percent uptake for different penetrant of composites material at $30^{\circ} \mathrm{C}$

The crosslinking density was calculated by the help of equilibrium swelling measurement. A sample dimension about $250 \times 250 \times 2$ mm was cut from the rubber sample. To assess the cross-linking density, EPDM/SBR composites were soaked in toluene for three days at $23^{\circ} \mathrm{C}$, with the toluene being replaced with new solvent (toluene) every day. An immersion test is performed to examine the nanofiller-rubber matrix interaction. Figure 7, shows the molecular weight of the polymer between the crosslinks $\left(\mathrm{M}_{\mathrm{c}}\right)$ and crosslinking density of EPDM/SBR blend composites with different proportion of HNTs. The obtained result shows an increasing trend in crosslinking density after loading the HNTs. The crosslinking density is determined in part by the molecular weight of the polymer between the crosslinks $\left(M_{c}\right)$. The $M_{c}$ values of HNTs filler filled EPDM/SBR nanocomposites are lower than those of unfilled EPDM/SBR nanocomposites. With increased HNTs content, the molar mass between crosslinks (Mc) decreased. The accessible volume between consecutive crosslinks reduced as the Mc values declined. As the amount of HNTs in the EPDM/SBR-HNTs nanocomposites increased, the crosslinking density also increased. Tensile strength, tear strength, hardness, and abrasion resistance are all improved by increasing crosslinking density.

The FE-SEM micrograph of the fractured tensile surface are shown in Fig. 8 (a) EPDM/SBR blends, (b) EPDM/SBR composites containing 6 phr HNTs and (c) EPDM/SBR composites containing $10 \mathrm{phr}$ HNTs. It can be concluded that the tensile fractured morphology surface of unfilled EPDM/SBR was relatively smooth (Fig. 8 (a)). For EPDM/SBR reinforced with 10 phr composite, the tensile fractured surface exhibited notable undulating stripes and rough characteristics (Fig. 8 (c)). In comparison, the tensile fractured surface of EPDM/SBR reinforced with 6 phr HNT shows large deformation and many tear folds (Fig. 8(b)), and no noticeable curatives (zinc oxide, stearic acid, sulphur, etc) particles were observed, showing excellent compatibility and good interfacial bond strength between HNTs and EPDM/SBR compound due to the $\mathrm{SiO}_{2}-\mathrm{Al}_{2} \mathrm{O}_{3}$ present in the HNTs filler, which was reliable with the improved tensile strength of the composite.

\section{Conclusions}

EPDM/SBR with various HNT loadings was prepared in this research, tensile properties, tear strength, hardness, abrasion, and swelling resistance tests were conducted and analyzed. Compared with EPDM/SBR blend, addition of HNTs resulted in $109 \%$ increase of tensile strength, $45 \%$ increase of 100 percent modulus and $11 \%$ increase of hardness. The improved interactions between the nano-filler and the rubber matrix increased the composites' strength and stiffness, reducing their ductility. The HNTs were found to act as a reinforcing agent in the crosslinking process.

\section{Declarations}

\section{Ethics approval and consent to participate}

Research involving No Human Participants and Animals

\section{Consent for publication}

The contents of this manuscript have not been copyrighted or published previously.

The contents of this manuscript are not now under consideration for publication elsewhere.

\section{Availability of data and materials}

Not Applicable

\section{Competing interests}




\section{Funding}

Not Applicable

\section{Authors' contributions}

All authors of this research paper have directly participated in the planning, execution, or analysis of this study

\section{Acknowledgements}

The authors thank Dr. G. Anand, Department of Mechanical Engineering, MVJ College of Engineering, Bangalore, India for her continuous support and encouragement throughout the work. We are grateful to MAEON Laboratories Section, Chennai for her help in preparing the materials and Technical Support for providing the set-up of all testing.

\section{References}

1. Younan, A.F.; Abd-El-Messieh, S.L.; Gasser, A.A. Electrical and mechanical properties of ethylene propylene diene monomer-chloroprene rubber blend loaded with white and black fillers. J. Appl. Polym. Sci. 1998, 70 (10), 2061-2068.

2. Arayapranee, W.; Rempel, G.L. A comparative study of the cure characteristics, processability, mechanical properties, ageing, and morphology of rice husk ash, silica and carbon black filled 75:25 NR/EPDM blends. J. Appl. Polym. Sci. 2008, 109, 932-941.

3. K Senthilvel, S Vishvanathperumal, B Prabu, L John Baruch, Studies on the morphology, cure characteristics and mechanical properties of acrylonitrile butadiene rubber with hybrid filler (carbon black/silica) composite, Polymers and Polymer Composites, 2016, 24, 473-480.

4. S Vishvanathperumal, S Gopalakannan, Reinforcement of ethylene vinyl acetate with carbon black/silica hybrid filler composites, Applied Mechanics and Materials, 2016, 852, 16-22.

5. Pasbakhsh, P.; Ismail, H.; Ahmad Fauzi, M.N.; Abu Bakar, A. The partial replacement of silica or calcium carbonate by halloysite nanotubes as fillers in ethylene propylene diene monomer composites. J. Appl. Polym. Sci. 2009, 113 (6), 3910-3919.

6. Ismail, H.; Pasbakhsh, P.; Ahmad Fauzi, M.N.; Abu Bakar, A. Morphological, thermal and tensile properties of halloysite nanotubes filled ethylene propylene diene monomer (EPDM) nanocomposites. Polym. Test 2008, 27, 841-850.

7. Arroyo, M.; Lopez-Manchado, M.A.; Herrero, B. Organomontmorillonite as substitute of carbon black in natural rubber compounds. Polymer 2003, 44 , 2447-2453.

8. Choi, S.S.; Nah, C.; Lee, S.G.; Joo, C.W. Effect of filler-filler interaction on rheological behavior of natural rubber compounds filled with both carbon black and silica. Polym. Int. 2003, 52, 23-28.

9. S Vishvanathperumal, S Gopalakannan, Effects of the nanoclay and crosslinking systems on the mechanical properties of ethylene-propylene-diene monomer/styrene butadiene rubber blends nanocomposite, Silicon, 2019, 11, 117-135.

10. S Vishvanathperumal, S Gopalakannan, Swelling properties, compression set behavior and abrasion resistance of ethylene-propylene-diene rubber/styrene butadiene rubber blend nanocomposites, Polymer Korea, 2017, 41, 433-442.

11. S Vishvanathperumal, G Anand, Effect of Nanoclay/Nanosilica on the Mechanical Properties, Abrasion and Swelling Resistance of EPDM/SBR Composites, Silicon, 2020, 12, 1925-1941.

12. S Vishvanathperumal, V Navaneethakrishnan, S Gopalakannan, The Effect of Nanoclay and Hybrid Filler on Curing Characteristics, Mechanical Properties and Swelling Resistance of Ethylene-Vinyl Acetate/Styrene Butadiene Rubber Blend Composite, Journal of Advanced Microscopy Research, $2018,13,469-476$.

13. S Vishvanathperumal, V Navaneethakrishnan, G Anand, S Gopalakannan, Evaluation of Crosslink Density Using Material Constants of EthylenePropylene-Diene Monomer/Styrene-Butadiene Rubber with Different Nanoclay Loading: Finite Element Analysis-Simulation and Experimental, Advanced Science, Engineering and Medicine, 2020, 12, 632-642.

14. Hanafi Ismail, Siti Zuliana Salleh, and Zulkifli Ahmad, Curing Characteristics, Mechanical, Thermal, and Morphological Properties of Halloysite Nanotubes (HNTs)-Filled Natural Rubber Nanocomposites, Polymer-Plastics Technology and Engineering, 2011, 50, $681-688$.

15. Zohre Karami, Omid Moini Jazani, Amir H. Navarchian, Mohammad Karrabi, Henri Vahabi, Mohammad Reza Saeb, Well-cured silicone/halloysite nanotubes nanocomposite coatings, Progress in Organic Coatings 129 (2019) 357-365.

16. Liu, M.; Guo, B.; Lei, Y.; Du, M.; Cai, X.; Jia, D. Properties of halloysite nanotubes-epoxy resin hybrids and the interfacial reactions in the systems. J. Nanotechnology 2007, 18, $455703-455711$

Loading [MathJax]/jax/output/CommonHTML/jax.js 
17. Rooj, S.; Das, A.; Thakur, V.; Mahaling, R.N.; Bhowmick, A.K.; Heinrich, G. Preparation and properties of natural nanocomposites based on natural rubber and naturally occurring halloysite nanotubes. J Mater. Design 2010, 31 (4), 2151-2156.

18. 13. Paskbakhsh, P.; Ismail, H.; Ahmad Fauzi, M. N.; Abu Bakar, A. Polym. Test. 2009, 28, 548.

19. H. Ismail, P. Pasbakhsh, M.N.A. Fauzi, A.A. Bakar, Morphological, thermal and tensile properties of halloysite nanotubes filled ethylene propylene diene monomer (EPDM) nanocomposites, Polym. Test. 27 (2008) 841-850.

33. Manoj KC, Kumari P, Rajesh C, Unnikrishnan G (2010) Aromatic liquid transport through filled EPDM/NBR blends. J PolymRes 17: 1-9

34. Sujith A, Unnikrishnan G (2006) Molecular sorption by heterogeneous natural rubber/poly(ethylene-co-vinyl acetate) blend systems. J PolymRes 13:171-180

35. Thomas PC, Tomlal JE, Selvin TP, Thomas S, Joseph K (2010) High-performance nanocomposites based on acrylonitrile butadiene rubber with fillers of different particle size: Mechanical and morphological studies. Polymer Composites 31:1515-1524

36. Flory PJ, Rehner J (1943). Statistical mechanics of cross-linked polymer networks I rubber like elasticity J Chem Phys 11:512

37. Naseri ASZ, Arani AJ (2015) A comparison between the effects of gamma radiation and sulfur cure system on the microstructure and crosslink network of (styrene butadiene rubber/ethylene propylene diene monomer) blends in presence of nanoclay. Radiat Phys Chem 115:68-74

38. Noriman NZ, Ismail H (2012) Properties of styrene butadiene rubber (SBR)/recycled acrylonitrile butadiene rubber (NBRr) blends: the effects of carbon black/silica (CB/silica) hybrid filler and silane coupling agent, Si69. J Appl Polym Sci 124:19-27

\section{Figures}

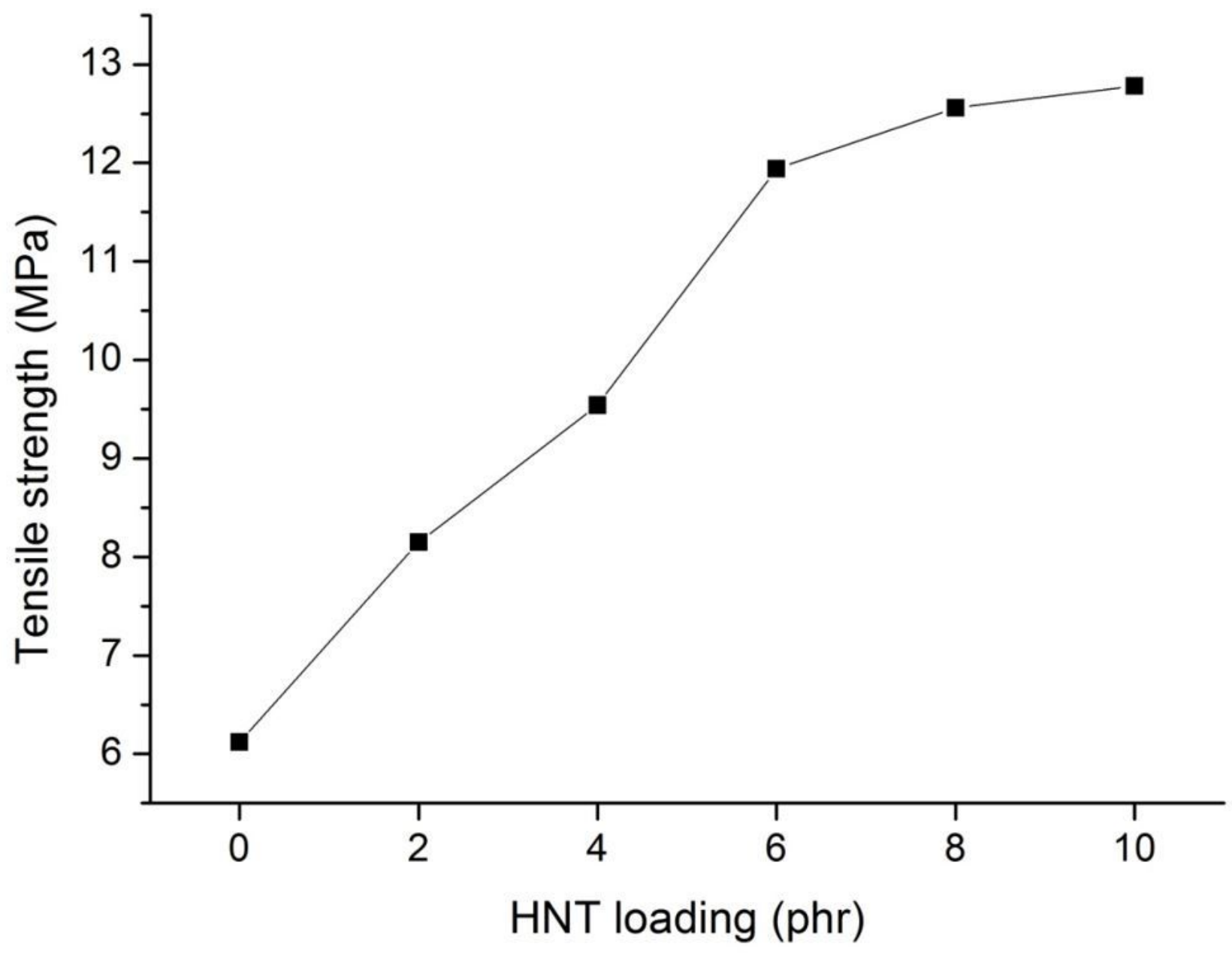

Figure 1 


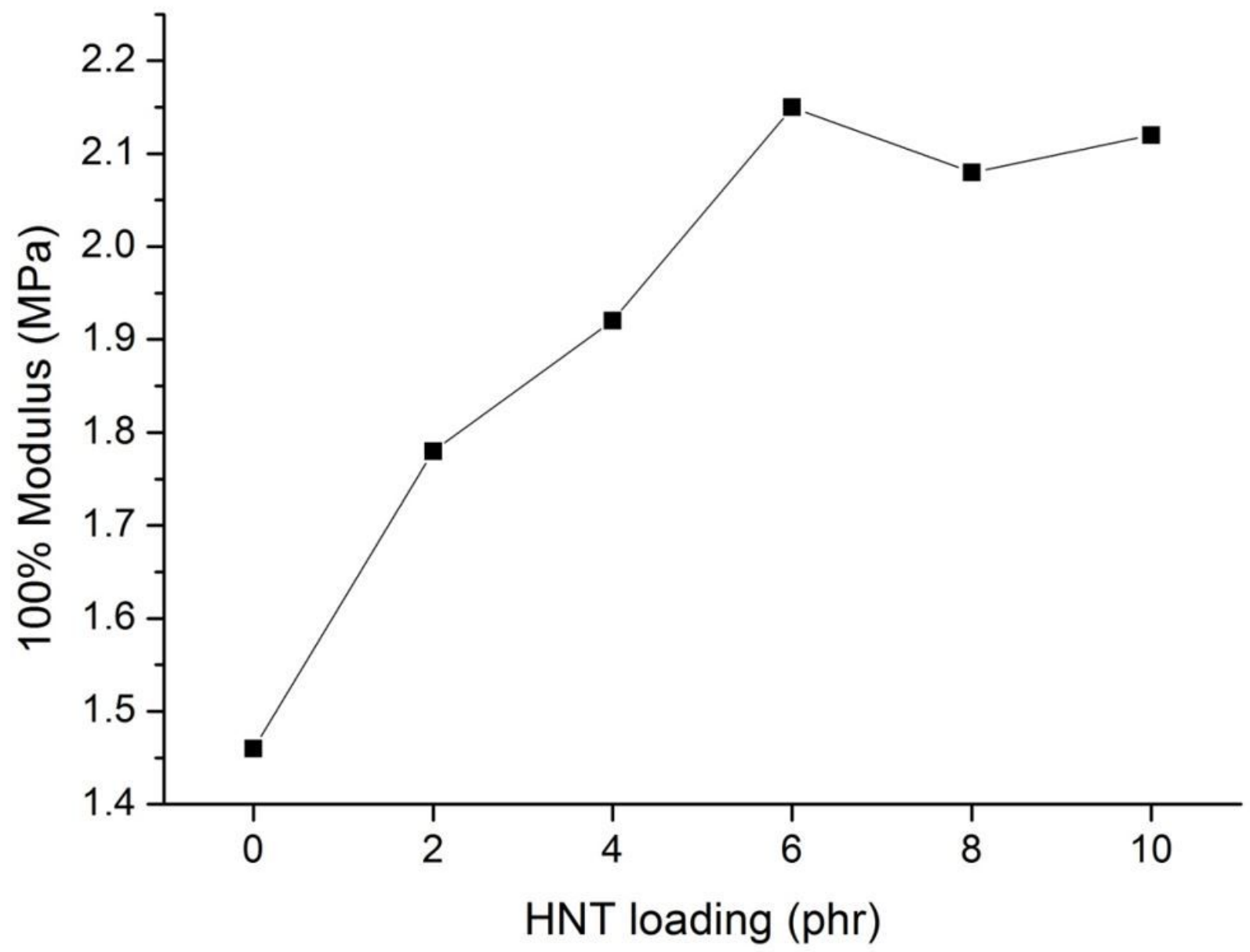

Figure 2

$100 \%$ modulus of the EPDM/SBR composites 


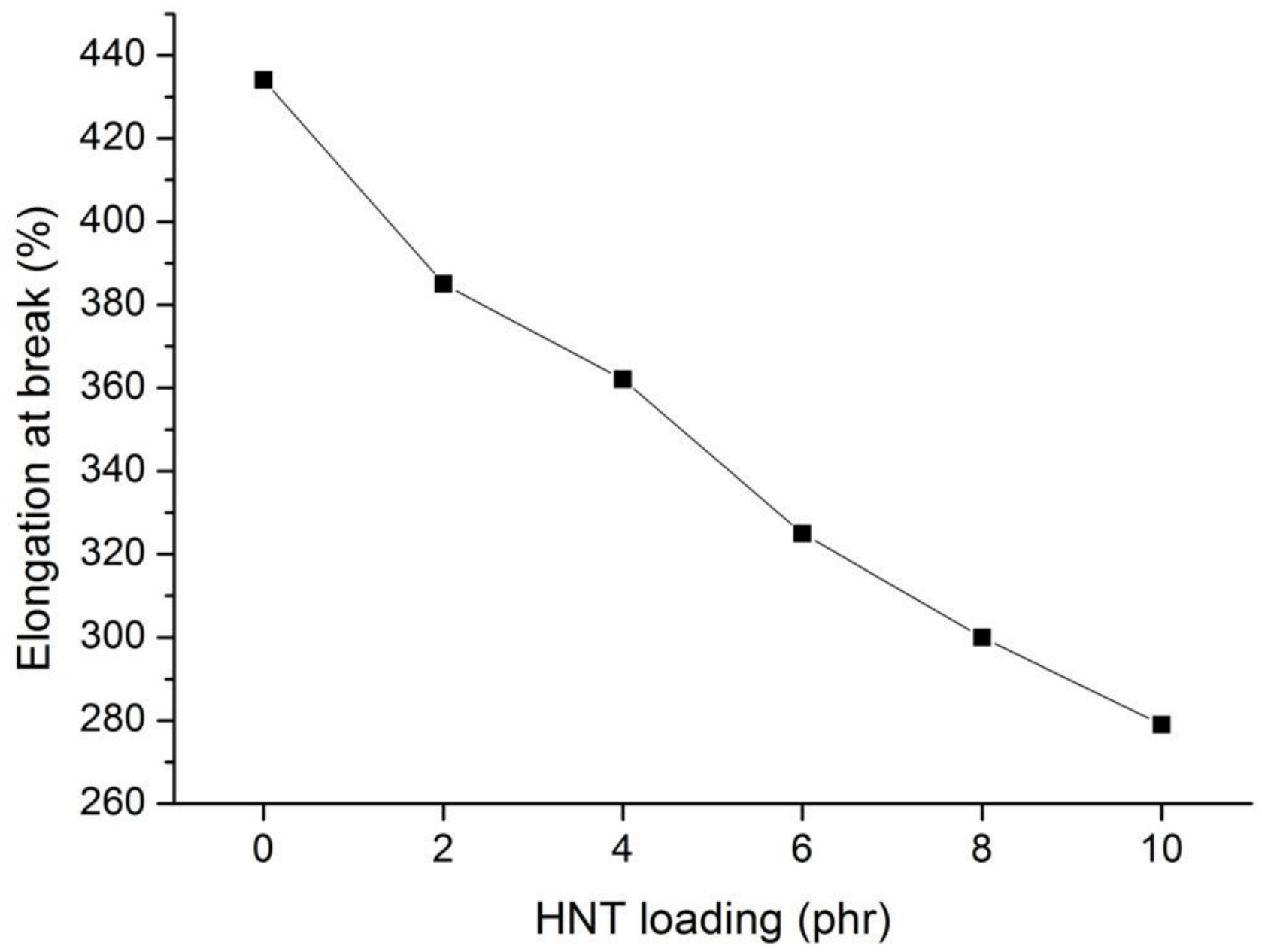

Figure 3

Elongation at break of the EPDM/SBR composites 


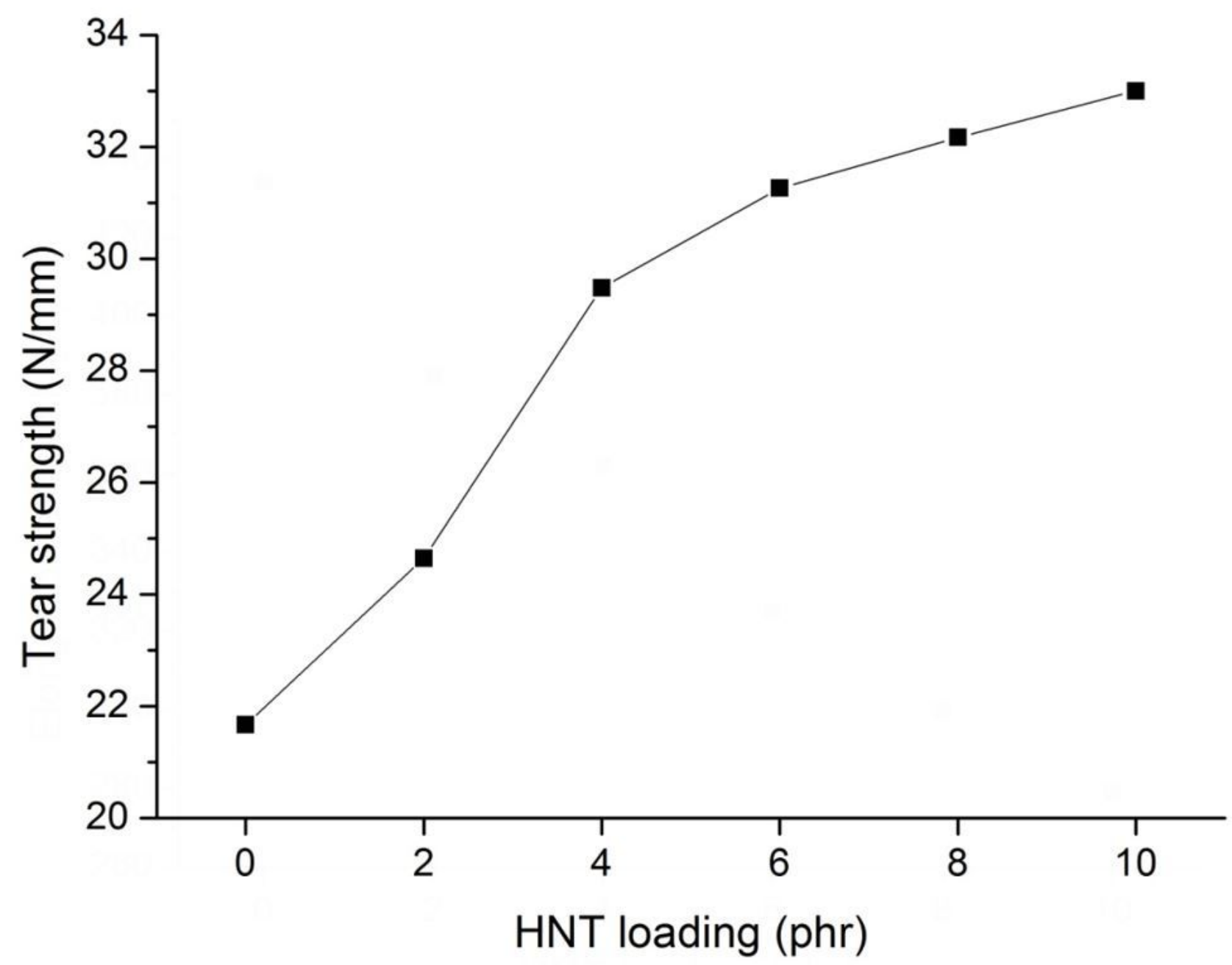

Figure 4

Tear strength of the EPDM/SBR composites 


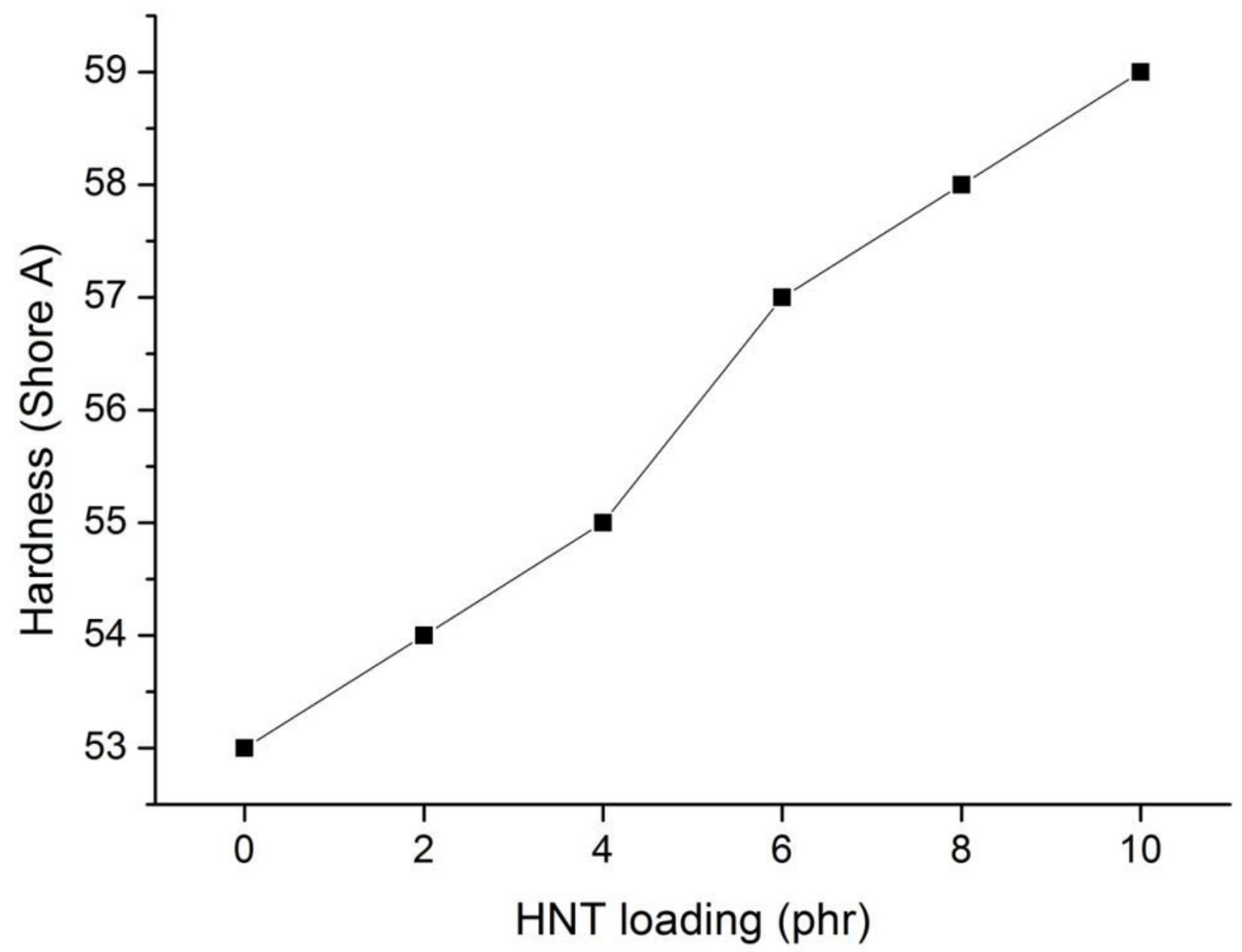

Figure 5

Hardness of the EPDM/SBR composites 


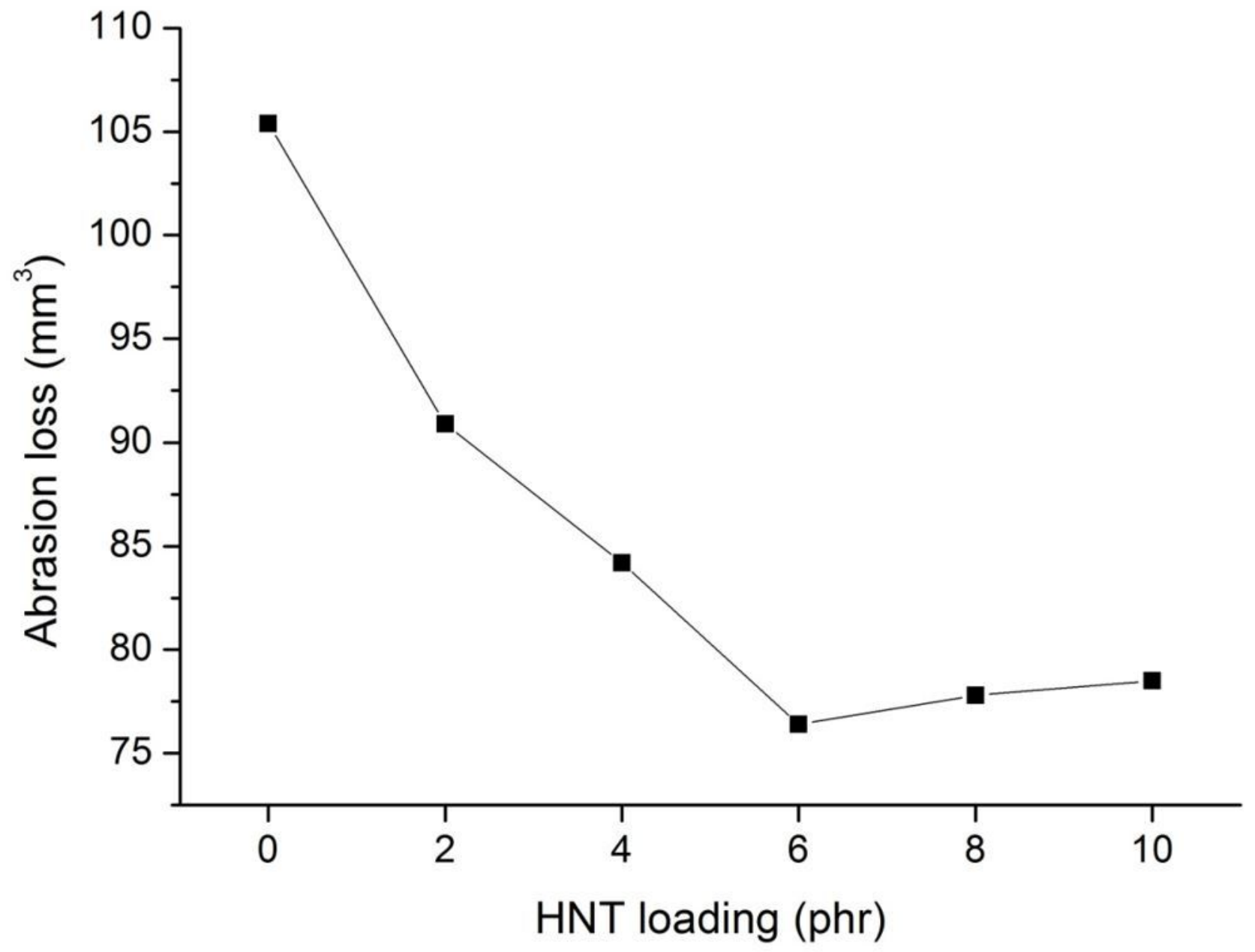

Figure 6

Abrasion loss of the EPDM/SBR composites 


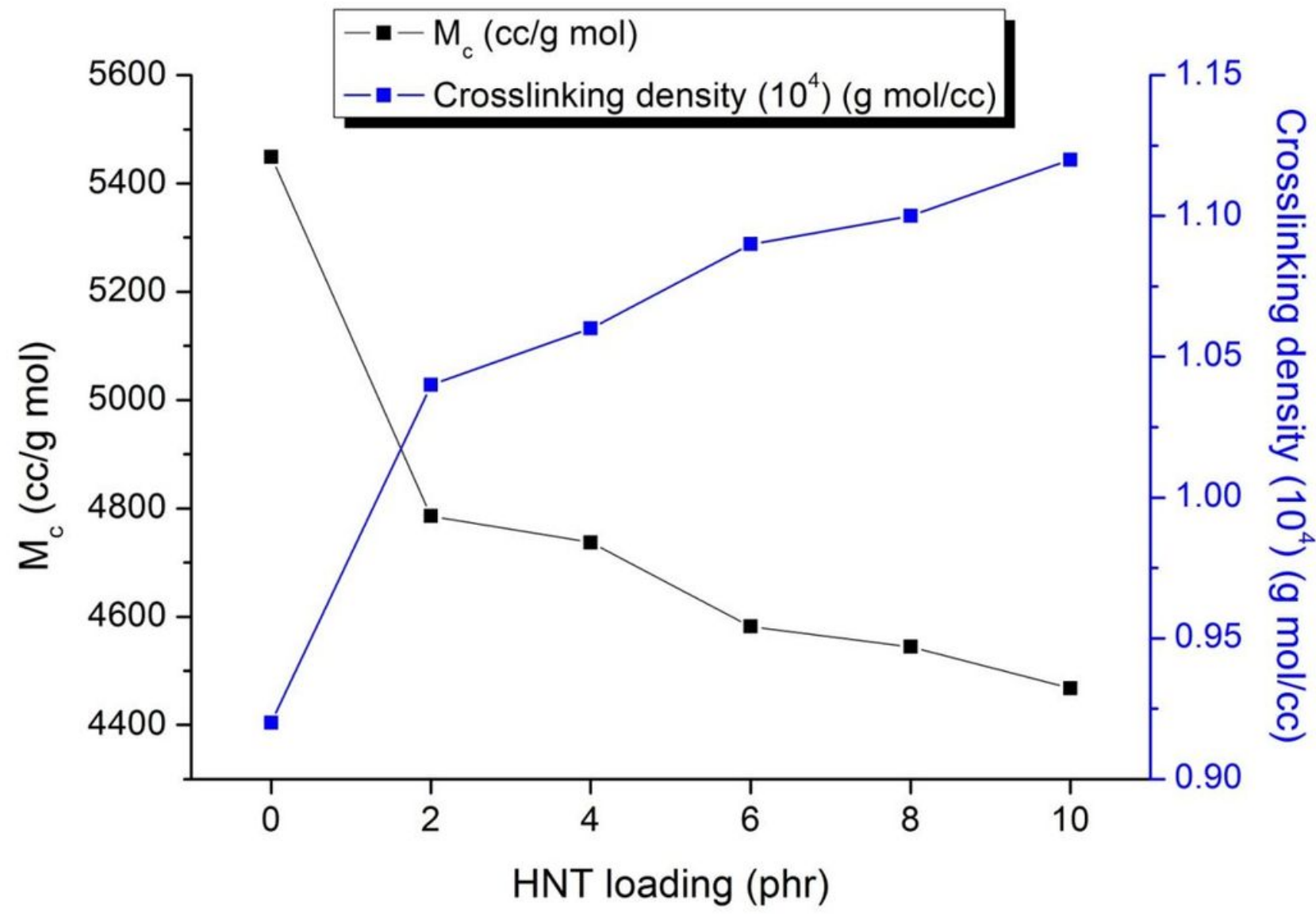

Figure 7

Molecular weight of the polymer between the crosslinks (Mc) and crosslinking density of the EPDM/SBR composites 


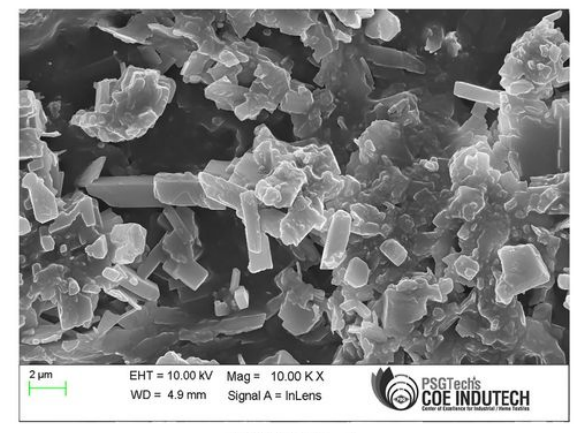

(a) EPDM/SBR blends

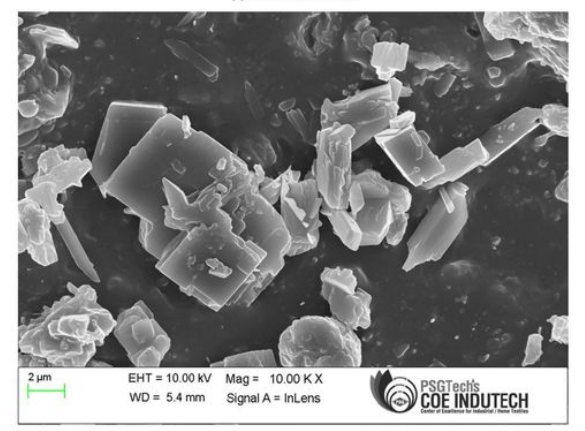

(b) EPDM/SBR composites containing 6 phr HNTs

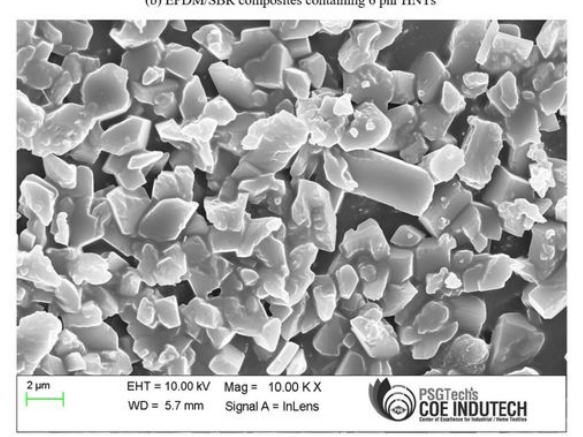

(c) EPDM $/ \mathrm{SBR}$ composites containing 10 phr HNTs

Figure 8

The tensile fractured surfaces of nanosilica filled EPDM/SBR composites 